\title{
Spastic paraplegia, optic atrophy, microcephaly with normal intelligence, and XY sex reversal: a new autosomal recessive syndrome?
}

Ahmad S Teebi, Steven Miller, Harry Ostrer, Patrice Eydoux, Céline Colomb-Brockmann, K Oudjhane, G Watters

\begin{abstract}
Two female sibs of first cousin Iranian parents were found to have the syndrome of spastic paraplegia, optic atrophy with poor vision, microcephaly, and normal cognitive development. Karyotype analysis showed a normal female constitution in one and a male constitution $(46, X Y)$ in the other. The XY female showed normal female external genitalia, normal uterus and tubes, and streak gonads. SRY gene sequencing was normal. We conclude that the present family probably represents a new autosomal recessive trait of pleiotropic effects including XY sex reversal and adds further evidence for the heterogeneity of spastic paraplegia syndromes as well as sex reversal syndromes. $(\Im$ Med Genet 1998;35:759-762)
\end{abstract}

Division of Medical Genetics A-608, The Montreal Children's Hospital and McGill University, 2300 Tupper Street, Montreal, Quebec, Canada H3H 1 P3

A S Teebi

P Eydoux

Division of Neurology, The Montreal

Children's Hospital and McGill University,

Montreal, Quebec,

Canada

$S$ Miller

G Watters

Human Genetics

Program, Department of Pediatrics, New York University Medical Center, New York,

USA

H Ostrer

C Colomb-Brockmann

Department of

Medical Imaging, The

Montreal Children's

Hospital and McGill

University, Montreal,

Quebec, Canada

K Oudjhane

Correspondence to:

Dr Teebi.

Received 23 October 1997 Revised version accepted for publication

4 February 1998
Keywords: spastic paraplegia; optic atrophy; microcephaly; sex reversal

Hereditary spastic paraplegia (HSP) is a heterogeneous group of spinocerebellar degeneration disorders that are classified as nonsyndromic, "pure", and syndromic. The nonsyndromic form is usually autosomal dominant (MIM 182600'); however, autosomal recessive and $\mathrm{X}$ linked recessive forms exist. ${ }^{2}{ }^{3}$ The syndromic forms have been variably associated with ataxia, optic atrophy, extrapyramidal abnormalities, muscular dystrophy, and mental retardation. Less common associations include ichthyosis, vitiligo, premature greying of hair, retinal dystrophy, and brachydactyly, among others. ${ }^{4-10}$ Syndromic HSP is often considered to be autosomal recessive and appears to be more frequent in Middle Eastern populations.

Sex reversal syndromes also constitute a heterogeneous group and include syndromes with and without involvement of the SRY gene, which is implicated in male differentiation. ${ }^{11-13}$

We report two sisters of consanguineous parents with infantile onset spastic paraplegia, optic atrophy, microcephaly with normal cognitive development, and $\mathrm{XY}$ sex reversal in one.

\section{Case reports}

PATIENT 1

This patient was one of female twins; the other was stillborn with no obvious anomalies. The pregnancy was otherwise uneventful and delivery was normal at term in Iran. Birth weight was $2750 \mathrm{~g}$ and birth length was $50 \mathrm{~cm}$. There were no neonatal problems. At the age of 6 months the parents noticed that she had a problem with tone and posture. Though she could roll over at 6 months of age, she was unable to support herself sitting. On evaluation at the age of 1 year she was found to have a normal CT scan of the brain and was diagnosed as having spastic diplegia. She could communicate well and cognitive skills appeared normal.

On examination at 4 years 4 months of age she appeared an alert and pleasant child with an occipitofrontal circumference (OFC) of $44.5 \mathrm{~cm}$ ( $<5$ th centile) and a length of $87 \mathrm{~cm}(<5$ th centile) (fig 1). She was unable to get into a sitting or standing position independently, but was able to crawl. She was not dysmorphic and the skin showed a small hypopigmented area on the right thigh and an extensive Mongolian spot on her back. She spoke with some dysarthria in French and her native language. There was plagiocephaly with flattening of the left part of the occiput and prominence of the left ear. Ocular movements were full and she followed light but had markedly reduced vision. Hearing was nor-

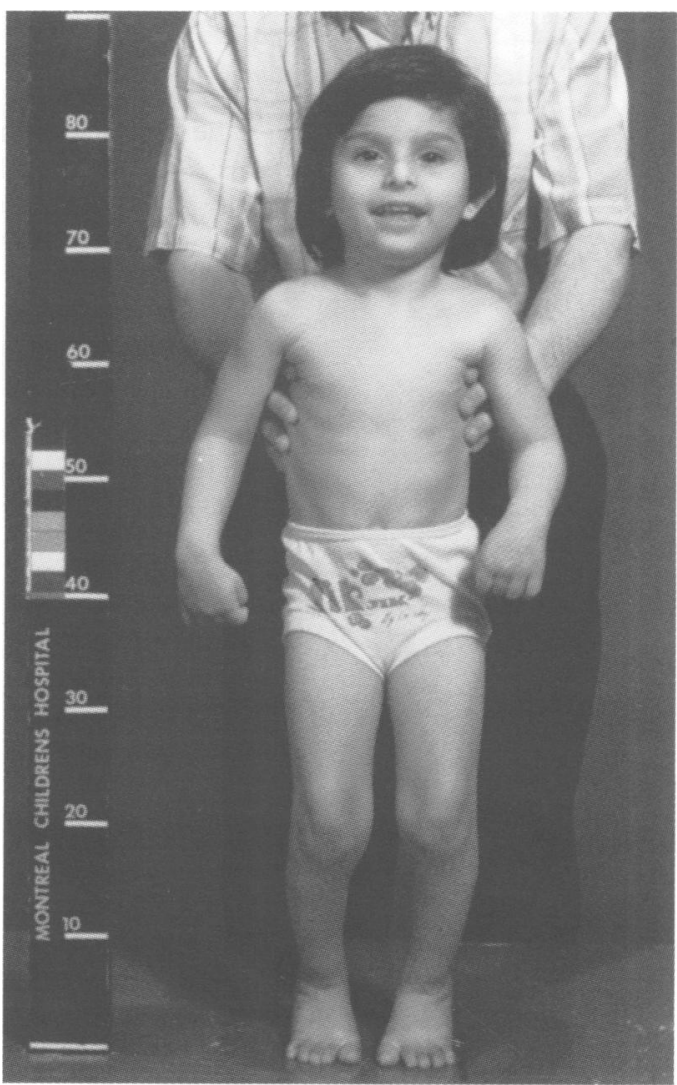

Figure 1 Patient 1: note the spastic posture. (Photographs reproduced with permission.) 


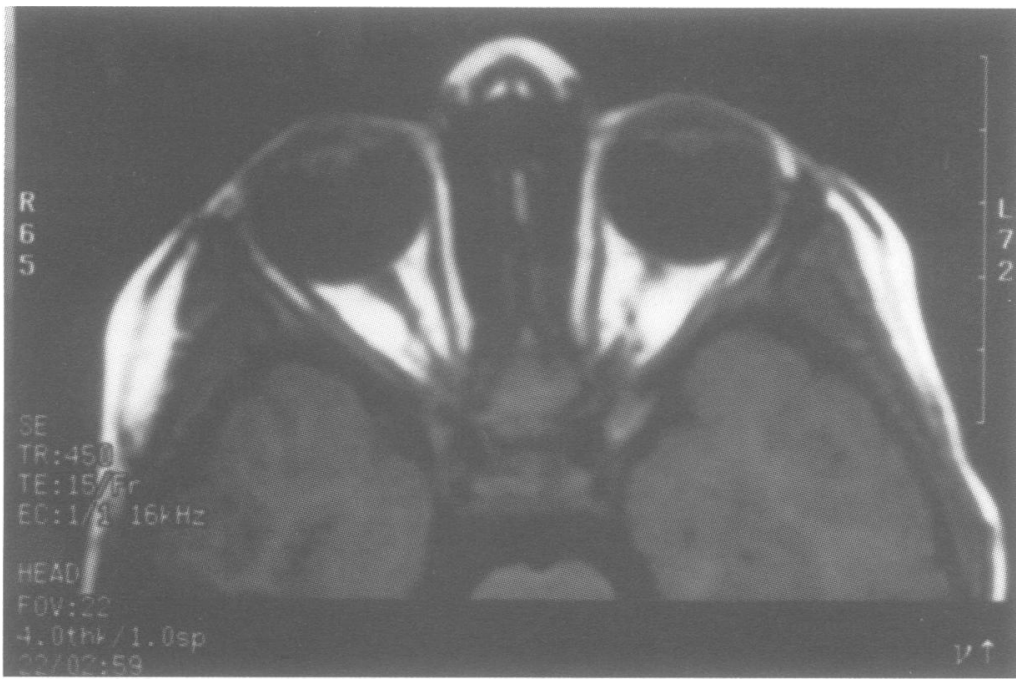

Figure 2 Patient 1: axial T, MR image of the orbits showing optic nerve atrophy.

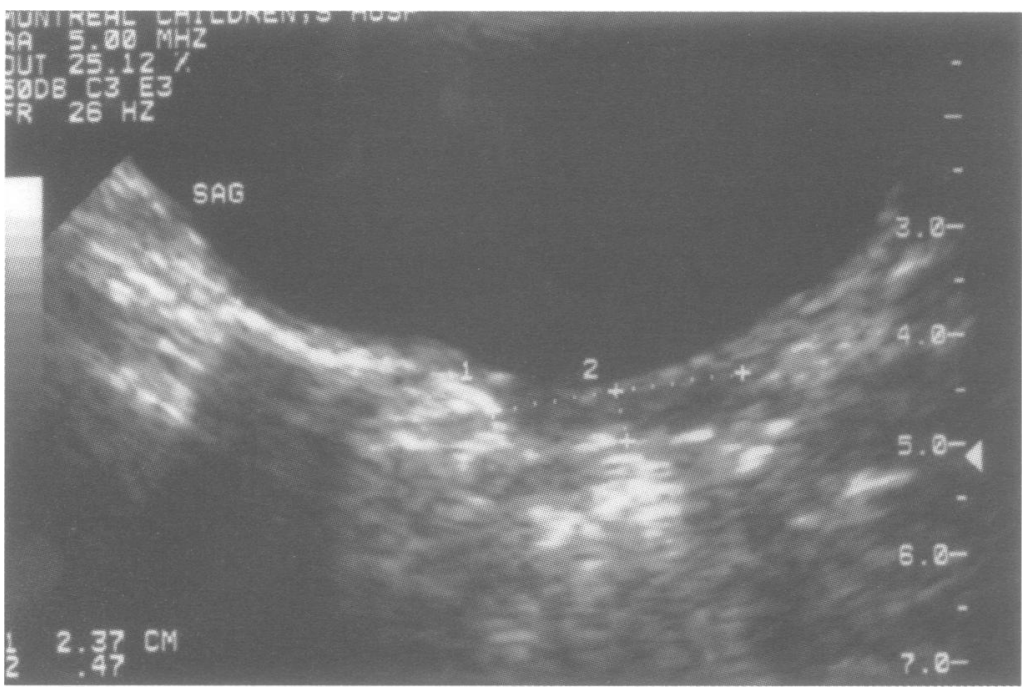

Figure 3 Patient 1: sagittal sonogram of the pelvis showing an infantile uterus (+ - +).

mal. There was no drooling. Stretch reflexes were brisk in the upper limbs and markedly brisk with clonus in the lower limbs. The extensor plantar responses were present bilaterally. Tone in all four extremities was increased. She had adductor spasm with scissoring and extensor thrusts of the lower extremities as she was placed in the standing position. There was difficulty with use of the upper limbs with grasp deficiency bilaterally. There was mild dystonic posturing of the hand when trying to reach for objects.

An MRI scan showed only a possible reduction in the size of the optic nerves bilaterally (fig 2). Ophthalmological examination also showed small optic nerves suggestive of optic atrophy with no pigmentary retinopathy and normal maculae. Electroretinogram (ERG) and visual evoked responses (VER) suggested normal retinal function and an optic nerve conduction defect. Skeletal survey showed bilateral coxa valga and no brachydactyly or cone shaped epiphyses. The karyotype was $46, X Y$. Pelvic ultrasound showed an infantile uterus and virtually no gonads were identified (fig 3). At 5 years of age she underwent diagnostic laparoscopy, which showed a normal uterus, and laparotomy with excision of streak gonads. Histopathological examination of specimens from both sides showed no evidence of normal ovarian or testicular tissues. Some nodular microscopic calcifications were noted. Hormonal profile before surgery showed that $\mathrm{LH}$ was $<1.5 \mathrm{U} / 1$ (normal $0-2$ ), FSH $23.5 \mathrm{U} / 1$ (normal 0-5), testosterone 0.5 $\mathrm{mmol} / \mathrm{l}$ (normal 0-2), and dihydrotestosterone $0.75 \mathrm{mmol} / 1$ (normal 2.2-10.3). Electromyography and motor and sensory nerve conduction studies were normal. Somatosensory evoked responses were suggestive of an abnormality rostral to the dorsal column nuclei, most likely in the thalamocortical projections bilaterally. Auditory brainstem evoked responses showed normal brainstem conduction. Electroencephalogram showed focal epileptiform activity over the right occipital region as well as poor development of background for age, suggesting a moderately diffuse disturbance of cerebral activity. Urine organic acids were unremarkable with absence of 3-methylglutaconic acid.

PATIENT 2

This patient was born normally after 37 weeks of an unremarkable pregnancy. Birth weight was $2650 \mathrm{~g}$ and birth length was $48 \mathrm{~cm}$. There were no neonatal complications. Like her sister, she was noted to have problems with tone and posture at 6 months of age. On evaluation in Iran she was found to have a normal CT scan of the brain at 1 year of age and was diagnosed with spastic diplegia. She could communicate well with only slightly delayed language milestones. Cognitive skills were otherwise normal.

On examination at 2 years 6 months of age, her OFC was $43 \mathrm{~cm}(<5$ th centile) and her height was $80 \mathrm{~cm}$ ( $<5$ th centile) (fig 4$)$. She was alert and responsive. She had soft, cup shaped ears and her skin showed five small café au lait spots with no axillary or inguinal freckling. Ocular movements were full and she had normal facial movement with no drooling. Stretch reflexes were brisk in the upper limbs and brisker in the lower limbs with some clonus at the ankles. Tone was increased in all four extremities, particularly in the legs. She could not sit or stand independently. She had adductor spasm with scissoring and standing on tiptoes when placed upright.

An MRI scan, like her sister, showed only a possible reduction in the size of the optic nerves bilaterally, but her vision was less affected. Ophthalmological examination also showed small optic nerves suggestive of optic atrophy. Flash visual evoked responses suggested normal retinal function and an optic nerve conduction defect. Skeletal survey showed bilateral coxa valga. Karyotype analysis was normal. Pelvic ultrasound showed a prepubertal uterus and normal ovaries. Electromyography and motor and sensory nerve conduction studies were normal. Somatosensory evoked responses were suggestive of an abnormality rostral to the dorsal column nuclei, most likely in the thalamocortical projections bilaterally. Auditory brainstem evoked responses were normal. Electroencephalogram showed an abnormal pattern of 


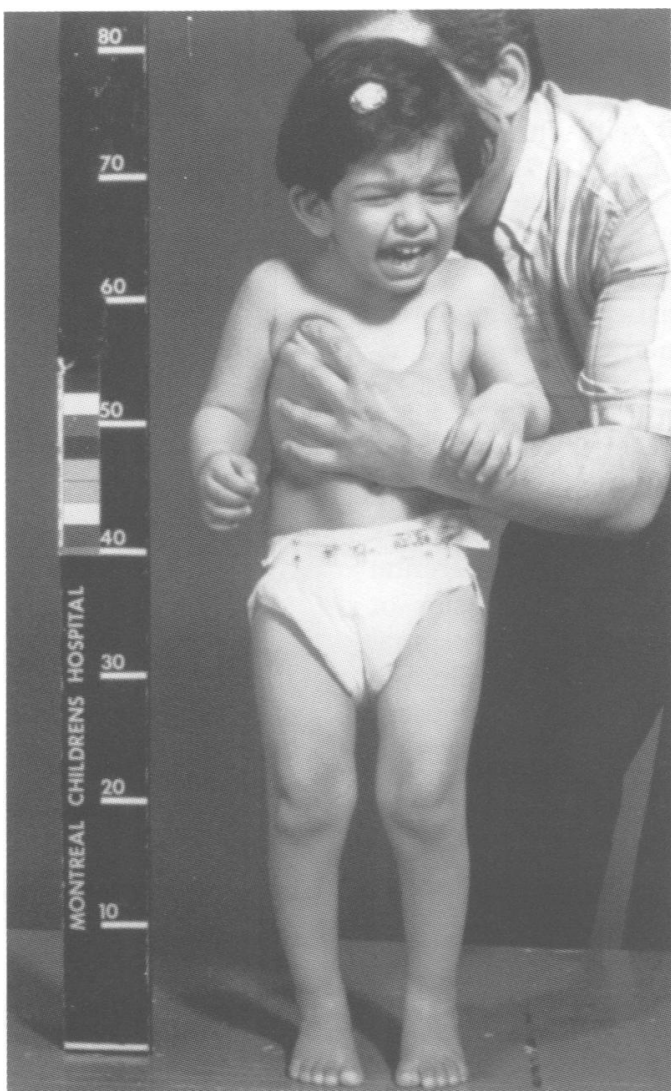

Figure 4 Patient 2: note the spastic posture.

reactivity of uncertain significance. Urinary organic acids were unremarkable with absence of 3-methylglutaconic acid.

At 4 years of age, OFC was $44.4 \mathrm{~cm}(<5$ th centile) and height was $85 \mathrm{~cm}(<5$ th centile). There were no cranial nerve abnormalities. Plantar responses were extensor bilaterally. She reached for objects awkwardly but better than her sister. Apart from short stature, the general medical examination was unremarkable.

FAMILY HISTORY

The probands were the second and third of three daughters of phenotypically normal Iranian parents who are first cousins. Their first pregnancy was a normal female. Neurological examination of the parents and their first child was unremarkable. There is no family history of neuromuscular disease, poor vision, female infertility, or other defects.

\section{CYTOGENETIC AND MOLECULAR CYTOGENETIC INVESTIGATIONS}

$\mathrm{G}$ banded chromosomes in peripheral blood of patient 1 showed a $46, \mathrm{XY}$ constitution. This was confirmed by high resolution $\mathrm{G}$ banding and fluorescence in situ hybridisation (FISH) probes specific for the $\mathrm{X}$ and $\mathrm{Y}$ centromeres (ONCOR). FISH probes from Xp21 were also used, which showed no duplication in this segment. Her sister's (patient 2) G banded chromosomes showed a $46, \mathrm{XX}$ normal female constitution. The parents' chromosomes were normal.

\section{SRY STUDIES}

Genomic DNA was extracted from the blood of the two patients, their parents, and their normal sister. PCR was conducted with primers that amplify the SRY open reading frame, plus about 90 bp upstream of start codon and $70 \mathrm{bp}$ downstream of stop codon. The PCR results were as expected from the karyotypic data. Only patient 1 and her father amplified the SRY region. Patient 1's SRY PCR product was subsequently cloned into vector $\mathrm{pCRII}$ and sequenced. The sequence showed no difference from the SRY published sequence. The results suggest that the patient's gonadal dysgenesis cannot be accounted for by a mutation in SRY.

\section{Discussion}

Syndromic or complicated HSP is a relatively common group which includes individually rare, clinically and genetically diverse disorders that have in common spasticity affecting predominantly the lower extremities. Optic atrophy is a frequently encountered association ${ }^{14-17}$ with additional peripheral neuropathy ${ }^{18}$ or ataxia, as in Behr's syndrome. ${ }^{19} 20$ Patients with this disorder have excessive excretion of 3-methylglutaconic acid and 3-methylglutaric acid in their urine. ${ }^{20}$ Mental retardation (MR) is also a common finding in many HSP syndromes ${ }^{5} 1^{17}$ 21-23 $^{\text {with }}$ additional cutaneous pigmentation disorder, ${ }^{24}$ transverse limb defects, ${ }^{25}$ or retinal dystrophy. ${ }^{27}$ Other individual syndromes include HSP with $M R$, retinitis pigmentosa, ${ }^{28}$ and deafness, ${ }^{29}$ HSP with peripheral neuropathy and painless foot ulcers, ${ }^{30}$ HSP with disordered pigmentation, peripheral neuropathy, and normal intelligence $^{31}$ and with ataxia, ${ }^{32}$ HSP with vitiligo, premature hair greying, peculiar facies, and normal intelligence, ${ }^{33} \mathrm{HSP}$ with congenital icthyosis, ${ }^{34}$ the syndrome of HSP, brachydactyly, cone shaped epiphyses, and normal intelligence or Fitzsimmons syndrome, ${ }^{3536}$ and others. ${ }^{15} 3740$

A significant overlap exists between some HSP syndromes, such that two or more of the so called new syndromes represent a single entity. The majority of these syndromes are autosomal recessive, many of which have been described in Arab families or Jews originating from Arab countries who often have high frequencies of consanguineous marriages. $^{2024-26} 303133$ However, in a few syndromes the inheritance is probably $\mathrm{X}$ linked recessive. ${ }^{14} 15234142$

However, the development of sex reversal in $\mathrm{XY}$ females may be the result of interference with testicular differentiation. This process is controlled mainly by the testicular determining factor (TDF) locus on distal Yp, which is the sex determining region $\mathrm{Y}$ (SRY), in addition to other genes located on the $\mathrm{X}$ chromosome and autosomes. ${ }^{1343}$ Mutations in SRY, however, only account for about $20 \%$ of cases of XY gonadal dysgenesis. ${ }^{12}{ }^{44}$ There is also evidence of an $\mathrm{Xp}$ region that can suppress testicular development in the presence of normal SRY. ${ }^{113}$ Many cases have been documented and the sex reversal associated with the presumptive locus appears to be the result of duplication and not disruption. ${ }^{45}{ }^{46}$ This locus was assigned to a region on distal $\mathrm{Xp} 21$ adjacent to the adrenal hypoplasia congenita critical region and has been termed "DSS" 
(dosage sensitive sex reversal). ${ }^{47}$ There is clear evidence now for an important locus involved in testicular development from studying campomelic dysplasia patients with chromosomal rearrangements involving 17q24-25 or without chromosomal rearrangements but with mutations of the SOX9 gene. ${ }^{48}{ }^{49}$ Other loci have also been implicated. ${ }^{13} 5051$

The constellation of spastic paraplegia, optic atrophy, dysarthria, and microcephaly with normal intelligence in two phenotypically female patients, with XY gonadal dysgenesis in one, is unlikely to be fortuitous. It may represent, however, a previously unrecognised syndrome, either in the category of syndromic HSP or XY sex reversal syndromes. The presence of parental consanguinity and the involvement of sibs of both genotypes is suggestive of an autosomal recessive trait with pleiotropic effects including $\mathrm{XY}$ sex reversal. This indicates that more loci are involved in testicular differentiation. We concur with Ferguson-Smith and Goodfellow ${ }^{12}$ that future identification and cloning of genes that regulate SRY, and are regulated by SRY, will be facilitated by careful clinical analysis of sex reversed patients like this.

We thank Susan Laurie for her secretarial assistance and Anaa Sajoo for her assistance in organising the investigations.

1 McKusick VA. Mendelian inheritance in man. A catalog of human genes and genetic disorders. 11 th ed. Baltimore: John Hopkins University Press, 1994

2 Harding AE. Classification of the hereditary ataxias and paraplegias. Lancet 1983;i:1151-5.

Reid E. Pure hereditary spastic paraplegia. $7 \mathrm{Med}$ Genet 1997;34:499-503.

4 Keppen LD, Leppert MF, O'Connell P, et al. Etiological heterogeneity in X-linked spastic paraplegia. Am f Hum Genet 1987;41:933-43.

5 Gigli GL, Diomedi M, Bernardi G, et al. Spastic paraplegia epilepsy, and mental retardation in several members of a family: a

6 Fink JK, Heiman-Patterson T, for the Hereditary Spastic Paraplegia Working Group. Hereditary spastic paraplegia advances in genetic research. Neurology 1996;46:1507-14.

7 Kobayashi H, Garcia CA, Alfonso G, Marks HG, Hoffman EP. Molecular genetics of familial spastic paraplegia: multitude of responsible genes. $\mathcal{F}$ Neurol Sci 1996;137:131 8.

8 Harding AE. Hereditary "pure" spastic paraplegia: a clinical and genetic study of 22 families. $\mathcal{f}$ Neurol Neurosur Psychiatry $1981 ; 44: 871-83$

9 Stoll C, Huber C, Alembik Y, Terrade E, Maitrot D. Dandy Walker variant malformation, spastic paraplegia, and mental retardation in two sibs. Am $\mathfrak{f}$ Med Genet 1990;37:124-7.

10 Harding AE. Hereditary spastic paraplegias. Semin Neurol 1993; 13:333-6.

11 Ostrer H. Sex determination. In: Adossi EY, Rock JA Rosenwaks Z, eds. Reproductive endocrinology, surgery and technology. New York: Raven Press, 1995.

12 Ferguson-Smith MA, Goodfellow PN. SRY and primary sex-reversal syndromes. In: Scriver CR, Beaudet AL, Sly W, Valle D, eds. The metabolic and molecular bases of inherite disease. 7th ed. New York: McGraw-Hill, 1995:739-48.

13 Simpson IL. Disorders of the gonads, genital tract and genitalia. In: Rimoin D, Connor JM, Pyeritz RE, eds. Emery and Rimoin's principles and practice of medical genetics.

14 Bruyn GW, Went LN. A sex-linked heredo-degenerative neurological disorder, Associated with Leber's optic atrophy. $\mathcal{F}$ Neurol Sci 1964;1:59-80.

15 Thurmon TF, Walker BA, Scott CI, Abott MH. Two kindreds with a sex-linked recessive form of spastic paraplegia. Birth Defects 1971;7:219-21.

16 Nyberg-Hansen R, Refsum S. Spastic paraparesis associated with optic atrophy in monozygotic twins. Acta Neurol Scand with optic atrophy in mor

17 Goldblatt J, Ballo R, Sachs B, Moosa A. X-linked spastic paraplegia: evidence for homogeneity with a variable paraplegia: evidence for homogeneity

18 Joshita Y, Atsumi T, Miyatake T. Two siblings with spastic paraplegia, optic atrophy and peripheral neuropathy. Rinsho Shinkeigaku-Clin Neurol 1982:22:901-8.

19 Landrigan PJ, Berenberg W, Bresnan M. Behr's syndrome: familial optic atrophy, spastic diplegia and ataxia. Dev Med Child Neurol 1973;15:41-7.
20 Sheffer RN, Zlotogora J, Elpeleg ON, Raz J, Ben-Ezra D Behr's syndrome and 3-methylglutaconic aciduria. $A m \mathcal{F}$ Ophthalmol 1992;114:494-7.

21 Baar HS, Gabriel AM. Sex linked spastic paraplegia. $A m \mathcal{F}$ Ment Defic 1966;71:13-18.

22 Gustavson KH, Modrzewska K, Erikson A. Hereditary spastic diplegia with mental retardation in two young siblings. Clin Genet 1989;36:439-41.

23 Ülkü A, Karasoy H, Karatepe A, Gokacy F. X-linked spastic paraplegia. Acta Neurol Scand 1991;83:403-6.

24 Mukamel M, Weitz R, Metzker A, Varsano I. Spastic paraparesis, mental retardation and cutaneous pigmenta-
tion disorder. A new syndrome. Am $\mathcal{f}$ Dis Child 1985;139: 1090-2.

25 Jancar J. Ectrodactyly, spastic paraplegia and mental retardation. F Ment Defic Res 1967;1:207-11.

26 Zlotogora J. Brief clinical report: mental retardation spasticity and transverse limb defects. Am $\mathcal{F}$ Med Genet 1987;26:221-3.

27 Sjaastad O, Berstad J, Gjesdahl P, Gjessing L. Homocarcinosis. 2. A familial metabolic disorder associated with spastic paraplegia, progressive mental deficiency, and retinal degeneration. Acta Neurol Scand 1976;53:275-90.

28 Mahloudji M, Chuke PO. Familial spastic paraplegia with retinal degeneration. fohns Hopkins Med f 1968;123:142-4

29 Gordon AM, Capute AJ, Konigsmark BW. Progressive quadriparesis, mental retardation, retinitis pigmentosa, and hearing loss: report of two sibs. Fohns Hopkins Med $\mathcal{F} 1976$; 138:142-5.

30 Al-Fawaz IM, Al-Tahan AR, Al-Rebdi FAA, Familusi JB Hereditary spastic paraplegia in association with sensory neuropathy in a Saudi family. Saudi Med F 1994;15:309-12.

31 Abdallat A, Davis SM, Farrage J, McDonald WI. Disordered pigmentation, spastic paraparesis and peripheral neuropathy in three siblings: a new neurocutaneous syndrome. F Neurol Neurosurg Psychiatry 1980;43:962-6.

32 Daras M, Tuchman AJ, David S. Familial spinocerebellar ataxia with skin hyperpigmentation. 7 Neurol Neurosurg Psychiatry 1983;46:743-4.

33 Lison M, Kornbrut B, Feinstein A, Hiss Y, Boichis $\mathrm{H}$ Goodman RM. Progressive spastic paraparesis, vitiligo, premature graying, and distinct facial appearance: a new premature graying, and distinct facial appearance: a new

34 Menamara JO, Curran JR, Itabashi H. Congenital ichthyosis with spastic paraplegia of adult onset. Arch Neurol 1975; 32:699-701.

35 Fitzsimmons JS, Guilbert PR. Spastic paraplegia associated with brachydactyly and cone shaped epiphyses. $f \mathrm{Med}$ Genet 1987;24:702-5.

36 Hennekam RCM. Spastic paraplegia, dysarthria, brachydactyly, and cone shaped epiphyses: confirmation of the Fitzsimmons syndrome. $\mathcal{F}$ Med Genet 1994;31:251-2.

37 Jampel RS, Okazaki H, Bernstein H. Ophthalmoplegia and retinal degeneration associated with spinocerebellar ataxias. Arch Opthalmol 1961;66:247.

38 Roe PF. Hereditary spastic parapiegia. 7 Neurol Neurosurg Psychiatry 1963;26:516-19.

39 Cross HE, McKusick VA, Breen WA. A new oculocerebral syndrome. $₹$ Pediatr 1967;70:398-406.

40 O'Neill BP, Swanson JW, Brown FR, Griffin JW, Moser HW. Familial spastic paraparesis: an adrenoleukodystrophy phenotype? Neurology 1985;35:1233-5.

41 Kenwrick S, Ionasescu V, Ionasescu G, et al. Linkage studies of X-linked recessive spastic paraplegia using DNA probes. Hum Genet 1986;73:264-6.

42 Donnelly A, Colley A, Crimmins D, Mulley J. A novel mutation in exon 6 (F236S) of the proteolipid protein gene is associated with spastic paraplegia. Hum Mutat 1996;8 384-5.

43 Gubbay J, Collignon J, Koopman P. A gene mapping to sex determining region of the mouse $\mathrm{Y}$ chromosome is a member of a novel family of embryonically expressed genes. Nature 1991;346:245-50.

44 Hawkins JR, Taylor A, Goodfellow PN, Migeon CJ, Smith $\mathrm{KD}$, Berkovitz GD. Evidence for increased prevalence of
$\mathrm{SRY}$ mutations in XY females with complete rather than partial gonadal dysgenesis. Am f Hum Genet 1992;51:979partial

45 Bernstein R, Jenkins T, Dawson B, et al. Female phenotype and multiple abnormalities in sibs with a $\mathrm{Y}$ chromosome and partial $\mathrm{X}$ chromosome duplication. $\mathrm{H}-\mathrm{Y}$ antigen and Xg blood group findings. $\mathcal{F}$ Med Genet 1980;17:291-300.

46 Ogata T, Hawkins JR, Taylor A, Matsuo N, Hata J, Goodfellow PN. Sex reversal in a child with a $46, \mathrm{XY}, \mathrm{Yp}+$ karyotype; support for existence of a gene(s), located in distal $\mathrm{Xp}$ involved in testis formation. $\mathcal{f}$ Med Genet 1992;29:226-30.

47 Bardoni B, Zanaaria E, Guioli S, et al. A dosage sensitive locus at chromosome Xp21 is involved in male to female sex reversal. Nat Genet 1994;7:497-501.

48 Young ID, Zuccolla JM, Maltby EL, Broderick NJ. Camptomelic dysplasia associated with a de novo $2 \mathrm{q} ; 17 \mathrm{q}$ reciprocal translocation. $₹$ Med Genet 1992;29:251-2.

49 Cameron FJ, Sinclair AH. Mutations in SRY and SOX9: testis determining genes. Hum Mutat 1997;9:388-95.

50 Greenberg F, Greesick MV, Carpenter RJ. The GardnerSilengo-Watchel syndrome: male pseudohermaphroditism Silengo-Watchel syndrome: male pseudohermaphroditism with micrognathia, cleft palate and con
defect. Am $尹$ Hum Genet 1987;26:59-64.

51 Crocker M, Coghill SB, Cortinho R. An unbalanced autosomal translocation $(7 ; 9)$ associated with feminization. Clin Genet 1988;34:70-3. 